\title{
On the Application of Virtual Instrument in Harmonic Measurement of Power System
}

\author{
Li Wang $^{1, \text { a }}$, Zhaohua Wang ${ }^{2}$ \\ ${ }^{1}$ Department of Energy Engineering, Yulin University, Yulin 719000, Shannxi, China \\ a278116312@qq.com
}

\begin{abstract}
Keywords: virtual instrument; power system; harmonic measurement; application; analysis
Abstract. With gradual development of power system, harmonic measurement of power system has attracted increasing attention. To realize harmonic measurement, we need to measure accurately using professional equipment. The research and development of virtual instrument is of great help for harmonic measurement of power system. For this end, in this article, based on harmonic measurement of power system, the author analyzes the operating principle of virtual instrument and probes into its practical application in harmonic measurement of power system. Hopefully through relevant study, this article could contribute to the development of power system.
\end{abstract}

\section{Introduction}

At present, computer technology is developing gradually. Many new technologies have sprung up and provided technical support for social and economic development. Among them, the virtual instrument, as innovative application testing equipment based on computer technology, can optimize hardware of conventional testing equipment. The application of such kind of virtual instrument in power system can effectively enhance the operating efficiency of power system and provide technical support for the fault detection and optimization, etc. of power system. Thus, in this article, the author studies the application of virtual equipment in harmonic measurement of power system. This is of positive significance for the perfection of power system.

\section{The Principle and Characteristics of Virtual Instrument}

The virtual instrument is a kind of computer equipment system. Such a system includes a virtual panel. In actual application, it can edit and output an expected graphical interface according to actual needs of users. Meanwhile, this equipment can perform the same testing function as other measuring equipment. Under software development and design, a virtual instrument can be coupled with modern instrument and equipment technology and computer-aided technology, etc. and be applied in power system. The hardware platform of virtual instrument includes a computer and I/O auxiliary equipment. The application of hardware system is mainly to acquire signals, convert between digital signals and analog signals and store data information, etc. With respect to data information processing, virtual instrument can improve the flexibility of instrument functions through software writing and data analysis, etc. [1].

Conventional virtual instrument can realize harmonic measurement of power system, but the efficiency is low and the cost input is high. The structure is shown below. The functions of conventional instruments and meters have great limitations in the development context of microelectronics, software, network technology and computer technology.

Nowadays, the virtual instrument applied in power system has been optimized on the basis of functions of conventional virtual instruments and equipment. The system application has higher flexibility and strong universality. At present, virtual instruments and equipment are widely applied in laboratory, aviation, manufacturing, auto industry, medicine and other fields[2]. The functions of conventional virtual instrument and new virtual instrument are compared as follows; 
Tab. 1 Comparison between the Functions of Conventional Virtual Instrument and New Virtual Instrument

\begin{tabular}{|c|c|}
\hline $\begin{array}{l}\text { Conventional } \\
\text { Instrument }\end{array}$ & New Virtual Instrument \\
\hline Hardware is the core & Software is the core \\
\hline $\begin{array}{l}\text { There are few } \\
\text { functions } \\
\text { instrument panel }\end{array}$ & $\begin{array}{l}\text { The functions are defined by the user and } \\
\text { modifiable on software }\end{array}$ \\
\hline Expensive & $\begin{array}{l}\text { Cheap, easy for secondary-development, strong } \\
\text { reconfiguration }\end{array}$ \\
\hline $\begin{array}{l}\text { Long update cycle of } \\
\text { technology }\end{array}$ & Short update cycle of technology \\
\hline Closed & $\begin{array}{l}\text { Open, flexible and associated with computer } \\
\text { technology }\end{array}$ \\
\hline Single function & $\begin{array}{l}\text { Can be connected with surrounding networks and } \\
\text { other equipment }\end{array}$ \\
\hline
\end{tabular}

\section{Harmonic Measurement of Power System}

In power system, set the operating cycle of system as $\mathrm{T}=\overline{\frac{2 \pi}{\Omega}}$ and this kind of power is non-sinusoidal power. When the system operation satisfies Dirichlet conditions, set the operating voltage of system as $\mathrm{u}(\omega t)$. The above voltage is decomposed. The decomposition result is $u(\Omega t)=a 0+\sum \infty n=1 c n \sin (n \Omega t+\Phi n)$. Such kind of decomposition result is Fourier series. When the set frequency is $n \Omega(n=2 / 3 / 4 \ldots)$, the above formula can be decomposed into harmonic terms. After a harmonic analysis, $\mathrm{u}(\mathrm{t})$ is sampled and transformed with cycle. Through an independent Fourier transform of discrete signals, the formula can meet practical demands for harmonic measurement of power system. Using this principle, power system staff can effectively improve the sub-harmonic ratio in current waveform distortion [3].

In actual measurement, power system staff makes a statistical analysis in view of the sub-harmonic ratio in current waveform distortion and voltage, to provide data support for subsequent system work. There exist harmonics in power system, which have a huge impact on the transmission loss and safety of power system. We need to lay more emphasis on harmonics of power system. In a power system, conventional harmonic interference may produce large measurement errors. Commonly-used perceptual instrument will be interfered by harmonics. While the voltage and current sensor and data acquisition (DAQ) card used by a virtual instrument can achieve multiple functions through LabVIEW programming. A virtual instrument is able to track the operating frequency of power network to the largest extent and inhibit harmonic leakage [4].

\section{System Design of Virtual Instrument Applied in Harmonic Measurement of Power System}

\subsection{Hardware design}

In the present design of virtual instrument applied in harmonic measurement of power system, the virtual instrument model is Evoc818HD. The application of this virtual instrument can effectively improve the application efficiency of system and realize innovation and optimization of system. A multi-channel DAQ card is employed in the new system. It has strong performance in the data transmission of power system. As a core element of this measurement system, the application of DAQ card in harmonic measurement can effectively enhance the accuracy of system. The parameters of Evoc818HD multi-channel DAQ card are shown in the table below: 
Tab. 2 Specific Parameters of Hardware Design

\begin{tabular}{|c|c|c|}
\hline $\begin{array}{l}\text { A/D } \\
\text { conversion chip }\end{array}$ & ADS7804 & $\begin{array}{ll}\text { Provide } & \text { convenience } \\
\text { for } & \text { technicians' } \\
\text { operation } & \end{array}$ \\
\hline $\begin{array}{l}\text { Number of analog } \\
\text { input channels }\end{array}$ & 16 & $\begin{array}{l}\text { Choose scanned } \\
\text { channels and enhance } \\
\text { data transmission } \\
\text { efficiency }\end{array}$ \\
\hline Sampling frequency & $100 \mathrm{kHz}$ & Highest \\
\hline $\begin{array}{l}\text { Input range of analog } \\
\text { signals }\end{array}$ & $\pm 10 \mathrm{~V}$ & $\begin{array}{l}\text { Guarantee the stable } \\
\text { operation of system } \\
\text { and measure } \\
\text { harmonics accurately }\end{array}$ \\
\hline Impedance & $10 \mathrm{M} \Omega$ & $\begin{array}{l}\text { In line with the } \\
\text { operating standard of } \\
\text { power system }\end{array}$ \\
\hline $\begin{array}{l}\mathrm{A} / \mathrm{D} \\
\text { conversion time }\end{array}$ & $10^{\mu S}$ & $\begin{array}{l}\text { Enrich } \\
\text { computer software } \\
\text { and hardware } \\
\text { resources and further } \\
\text { enhance the } \\
\text { application efficiency } \\
\text { of virtual instrument } \\
\text { technology }\end{array}$ \\
\hline
\end{tabular}

\subsection{Software design}

In the present harmonic measurement of power system, power system technicians use virtual instrument technology to optimize and innovate on the basis of conventional measuring instrument technology. In concrete application, the software design includes the following content:

Tab. 3 Software Design Modules

\begin{tabular}{lllll}
\hline $\begin{array}{l}\text { Module } \\
\text { Name }\end{array}$ & $\begin{array}{l}\text { Data Acquisition } \\
\text { Procedure }\end{array}$ & $\begin{array}{l}\text { Data } \\
\text { Processing } \\
\text { Procedure }\end{array}$ & $\begin{array}{l}\text { Result } \\
\text { Procedure }\end{array}$ & Display \\
\hline Core Element & Di-rectMemory Access & DAQ card & $\begin{array}{l}\text { C language } \\
\text { programming } \\
\text { display interface }\end{array}$ \\
Function & $\begin{array}{l}\text { Give play to the advantages of } \\
\text { virtual instrument technology, judge drivers } \\
\text { group and classify data on the }\end{array}$ & $\begin{array}{l}\text { Analyze ata display } \\
\text { data analysis } \\
\text { process and results }\end{array}$ \\
& $\begin{array}{l}\text { DAQ card } \\
\text { Quick data transmission and } \\
\text { easy processing }\end{array}$ & $\begin{array}{l}\text { High precision } \\
\text { and high } \\
\text { flexibility }\end{array}$ & $\begin{array}{l}\text { Visual results and } \\
\text { appropriate } \\
\text { analysis }\end{array}$ \\
\hline
\end{tabular}

4.3 Simulation analysis

We apply the virtual instrument in harmonic measurement of power system. When measurement results are obtained, to guarantee the authenticity of data and information, we need to identify system application using simulation analysis. During harmonic analysis of power system, the software of virtual instrument is used to establish custom use boundaries. In a modular system, different function modules are selected according to measurement needs of technicians to offer integrated services of system [5]. In actual application, simulation parameters are as follows: 
Tab. 4 Simulation Parameters

\begin{tabular}{lll}
\hline $\begin{array}{l}\text { Parameter } \\
\text { Type }\end{array}$ & $\begin{array}{l}\text { Parameter } \\
\text { Standard }\end{array}$ & Characteristic and Advantage \\
\hline $\begin{array}{l}\text { Current } \\
\text { Transformer }\end{array}$ & $80 \mathrm{kHz}$ & $\begin{array}{l}\text { Measure accurately, meet the demands of three-phase } \\
\text { fully-controlled bridge rectifier circuits }\end{array}$ \\
$\begin{array}{l}\text { Data } \\
\text { Transmission }\end{array}$ & NMA mode & $\begin{array}{l}\text { Input data using multiple modules, expand functions } \\
\text { of software and hardware platforms and realize } \\
\text { real-time data acquisition and transmission. }\end{array}$
\end{tabular}

In actual harmonic measurement of power system, the application of DAQ module in software design can effectively enhance data simulation accuracy of system and effectively avoid input errors in data acquisition to a certain extent. With respect to simulation result analysis, measurements are taken by the coordination between software and hardware modules of virtual instrument. The reliability of results is improved.

\section{Conclusion}

To sum up, in this article, the author analyzes the principle, structure and characteristics of the application of virtual instrument in harmonic measurement of power system and compares it with conventional instrument. Meanwhile, from the analysis of software and hardware modules of system, we optimize harmonic measurement. Finally, a simulation analysis is conducted on the system. Hopefully the accuracy of harmonic measurement could be improved through the simulation analysis.

\section{References}

[1] Sutherland P E. Harmonic measurements in industrial power systems[J]. IEEE Transactions on Industry Applications, 1995, 31(1):175-183.

[2] Dalali M, Jalilian A. Indices for measurement of harmonic distortion in power systems according to IEC 61000-4-7 standard[J]. Iet Generation Transmission \& Distribution, 2015, 9(14):1903-1912.

[3] Solovev D B, Shadrin A S. Instrument current transducer for measurements in asymmetrical conditions in three-phase circuits with upper harmonics[J]. International Journal of Electrical Power \& Energy Systems, 2017, 84:195-201.

[4] Xu X Y, Mindykowski J, Tarasiuk T, et al. Study of Harmonic Detection Methods under Non-Ideal Conditions in Ship Power Network[J]. Polish Maritime Research, 2015, 22(3):82-89.

[5] Ujile A, Ding Z. A dynamic approach to identification of multiple harmonic sources in power distribution systems[J]. International Journal of Electrical Power \& Energy Systems, 2016, 81:175-183. 